\title{
A (RE)CONSTRUÇÃO DO INDIVÍDUO: a sociedade de consumo como "contexto social" de produção de subjetividades
}

\author{
Anderson Moebus Retondar*
}

Resumo: O presente trabalho tem como objeto privilegiado de análise a configuração contemporânea da sociedade de consumo e as novas relações e processos sociais que esta engendra. A despeito das teses que reforçam o espraiamento do consumo como forma de massificação/homogeneização social, responsável por destituir a própria possibilidade de realização do indivíduo enquanto sujeito do processo social, caras ao pensamento frankfurtiano, especialmente através das obras de Adorno e Horkheimer, pretende-se aqui discutir em que medida, a partir da centralidade que o processo de consumo adquire no contexto das atuais sociedades, ocorreria um movimento inverso, marcado pelo fortalecimento de processos de individuação por intermédio de novas formas de construção de identidades e subjetividades mediadas pela atividade consumista. Trata-se, neste caso, de trabalho que procura discutir, a partir da perspectiva teórica do sociólogo americano John B. Thompson, em que medida a esfera do consumo se qualificaria enquanto um "contexto estruturado", a partir do qual dar-se-ia a produção de novas "formas simbólicas" que se transfigurariam em elementos de expressão de subjetividades sociais.

Palavras-chave: sociedade de consumo, cultura contemporânea, identidades, individualidade, subjetividades.

\footnotetext{
Professor do programa de pós-graduação e do curso de graduação em Ciência Sociais, e coordenador da área de Sociologia do Departamento de Ciências Sociais da Universidade Federal de Campina Grande (UFCG).E-mail: anderson.retondar@bol.com.br
}

Artigo recebido em 7 ago. 2007 e aprovado em 30 abr. 2007. 
A sociedade de consumo caracteriza-se, antes de tudo, pelo desejo socialmente expandido da aquisição "do supérfluo", do excedente, do luxo. Do mesmo modo, se estrutura pela marca da insaciabilidade, da constante insatisfação, onde uma necessidade preliminarmente satisfeita gera quase automaticamente outra necessidade, num ciclo que não se esgota, num continuum onde o final do ato consumista é o próprio desejo de consumo. ${ }^{1}$

O espraiamento dessa lógica - que se dá a partir das mudanças estruturais desenvolvidas no século XVIII na Europa ocidental, especialmente com a Revolução Industrial - acelera-se a partir da segunda metade do século XX, quando o universo do consumo passou a ganhar centralidade tanto como motor do desenvolvimento econômico quanto através da expansão do consumismo como elemento de mediação de novas relações e processos que se estabelecem no plano cultural das sociedades modernas.

Dentro dessa perspectiva, o consumo deixa de ser uma variável dependente de estruturas e processos a ele externos e passa a se constituir enquanto campo autônomo, caracterizando-se como importante objeto do conhecimento no âmbito das ciências sociais contemporâneas, especialmente no campo dos estudos sobre a cultura. $^{2}$

Esta questão nos informa, por si própria, sobre algo novo. Ou seja, quando o pensamento social começa a eleger as práticas de consumo enquanto objeto da análise científica, não apenas confere legitimidade a este campo, mas, fundamentalmente, revela algum tipo de mudança que se estabelece nas estruturas e processos constitutivos da ordem social global. A partir daí entram em cena duas questões que passam a orientar os estudos sobre consumo e suas relações com a atividade social: a primeira refere-se à centralidade que a produção de significados e processos simbólicos em geral passam a desempenhar no contexto da atividade social contemporânea; e a segunda preocupa-se com os significados sociais e os processos 
simbólicos que, agora, se encontram transpassados pelo universo do consumo.

Numa palavra, o campo da atividade consumista deixa de ser espaço da atividade econômica stricto sensu para se constituir enquanto campo de produção de significados e formas simbólicas.

Consumir passa, neste caso, a ser percebido como processo de mediação de relações sociais, transfigurando através desta atividade conflitos políticos, de gênero, distinções étnico-raciais, reprodução de valores entre um conjunto de outros elementos que são sustentados ou negados simbolicamente no interior deste campo.

Se as origens da sociedade de consumo estão localizadas no período de consolidação da própria modernidade na Europa ocidental dos séculos XVIII e XIX, é patente sua radicalização no contexto das sociedades contemporâneas, servindo agora como referência para construções intelectuais fortes como, por exemplo, a idéia de uma cultura de consumo que, segundo algumas abordagens, ${ }^{3}$ constituirse-ia como uma das chaves explicativas da própria dinâmica cultural na modernidade tardia.

Exageros à parte, parece fato corrente na atual teoria social que a lógica da produção, responsável pela manutenção e fortalecimento da noção de sociedade industrial na primeira metade do século $\mathrm{XX}$, se encontra, a partir das mudanças estruturais do capitalismo contemporâneo, perdendo crescentemente centralidade diante da lógica do consumo, a qual passaria a constituir a base de um tipo de organização social novo, autodenominado pós-industrial.

As mudanças no mundo da produção e do trabalho seriam, sob este viés de abordagem, os movimentos fundamentais a partir dos quais aconteceria essa passagem, de um lado, em decorrência da perda da centralidade da própria atividade produtiva como epicentro do novo capitalismo (Offe, 1989) e/ou, de outro, pela mudança no próprio modelo de acumulação, que passa a ser marcado pela 
flexibilidade tanto da produção quanto do consumo (Harvey, 1992).

Sob o primeiro aspecto da questão, Clauss Offe (1989) irá chamar a atenção para o que ele denomina "capitalismo desorganizado", marcado pela sobreposição do setor de serviços sobre o setor produtivo, associado ao declínio de uma ética do trabalho e, de modo decisivo, à perda da centralidade da atividade ocupacional como elemento constitutivo das identidades sociais nesta fase do capitalismo avançado.

Nessa perspectiva, este processo de descentralização do trabalho e da própria esfera da produção como lócus de constituição das identidades e, por extensão, da própria subjetividade social, cederia lugar a outros espaços onde essas identidades e subjetividades seriam produzidas.

Mesmo sem afirmar com precisão quais seriam esses novos espaços, Offe coloca um problema que nos parece ser pertinente e que passa a ser gradativamente contemplado por parte do pensamento sociológico que começa a compreender a esfera da demanda como lócus privilegiado a partir do qual se constituiriam, agora, identidades e manifestações de subjetividade social.

Evidentemente que, se se modificam os espaços da produção de significados, modifica-se, do mesmo modo, a lógica da produção tanto sob o aspecto dos meios quanto dos próprios agentes produtores. Se, no âmbito da sociedade industrial, os agentes se estruturam a partir de uma lógica essencialmente homogeneizante, no contexto do capitalismo avançado essa lógica parece se orientar em direção à fragmentação.

A própria noção de classe como elemento constituinte de identidades torna-se problemática na medida em que, com a perda da centralidade da atividade produtiva em relação à atividade de serviços, os critérios objetivos na demarcação das posições de 
classe se diluiriam. No interior desse contexto poderíamos falar de um deslocamento, onde as identidades passariam a ser constituídas a partir de um conjunto de esferas localizadas fora do espaço do trabalho, em grande medida entrelaçadas à dinâmica do consumo.

$\mathrm{Na}$ outra ponta da questão se coloca o problema do modelo da acumulação flexível e como ele passa a alterar as relações entre consumo, cultura e sociedade.

O modelo de acumulação flexível pressupõe, antes de tudo, uma ruptura com os princípios do modelo fordista de gerenciamento da produção, no que tange tanto à dinâmica do trabalho quanto à dinâmica do capital. Tanto num caso quanto no outro, flexibilizar a produção significa, em termos objetivos, capacitar a estrutura de produção para, num curto espaço de tempo, produzir produtos altamente diversificados, o que, por seu lado, somente é possível através da substituição crescente do trabalho manual especializado pelo trabalho intelectual e altamente volátil.

Sob esse aspecto, a ordem da produção passa a ser, ao contrário do princípio de padronização e homogeneização, organizada pelo princípio da fragmentação e efemeridade da produção, causando impacto direto sobre a esfera do consumo. Nesse caso, o modelo da acumulação flexível, aliado às novas tecnologias de produção, propiciaria a base para um mercado de bens altamente diversificado, visando cada vez mais uma maior aproximação entre o produtor e o consumidor, tentando adequar o máximo possível a produção às exigências mais particulares deste último.

Em termos propriamente sociológicos, essa mudança não é apenas uma mudança quantitativa que se dá no campo do consumo por intermédio da maior disponibilidade e variedade de bens. Ao contrário, reflete uma mudança na própria lógica social do consumo, que passa de uma relação de massificação do consumidor para uma hipertrofia de sua individualidade. 
A especialização do consumo através da fragmentação dos mais variados segmentos consumidores - processo que, segundo alguns ${ }^{4}$ foi impulsionado pelo modelo da acumulação flexível a partir da segunda metade do século XX - seria, neste caso, o principal elemento a partir do qual poderíamos então falar de uma passagem do sentido coletivo do consumo, precisamente sob o aspecto da homogeneização social, para um outro, marcado pelo princípio da individualização.

Por outro lado, se atribuirmos às práticas consumistas status de práticas significativas - e isto parece ser um elemento essencial que envolve o ato de consumo nas sociedades modernas-, a flexibilização da produção, responsável por gerar um consumo altamente diversificado, produzirá uma experiência cultural nova, marcada pela alta fragmentação dos significados sociais, responsável, assim, por um movimento constante de individualização orientado pelas práticas consumistas. ${ }^{5}$

Vista sob uma perspectiva puramente fenomenológica, a experiência contemporânea do consumo refletiria, de maneira objetiva, esta forma de individualização por intermédio do ato consumista.

A própria categoria "consumidor", em seu sentido abstrato e universal, parece estar sendo colocada em xeque em favor de variações que pressupõem uma multiplicidade de características sociais e culturais como sexualidade, etnia, identidades, gostos, etc., que são distintamente atribuídas pelos mais diversos segmentos consumidores, tanto pela publicidade quanto pela organização dos departamentos de marketing, que se tornaram decisivos nas empresas no sentido de orientar a própria atividade produtiva. ${ }^{6}$

Gostaríamos aqui de propor uma inversão do problema. Se tudo indica que o movimento de especialização do consumo resultaria de um conjunto de mudanças técnico-estruturais que o 
viabilizariam, a questão de fundo que o orienta não parece residir apenas nesta perspectiva mais visível de todo o processo.

Sob este aspecto, mais do que as mudanças ocorridas na estrutura do modelo capitalista de acumulação, acredito que o responsável por caracterizar uma das principais bases de reorganização do consumismo nas sociedades contemporâneas tenha sido a retomada do princípio da individualidade enquanto valor fundamental da modernidade.

Antes de tudo, a idéia de indivíduo deve ser percebida como uma construção social do mundo moderno, que se fundamenta nas transformações políticas, sociais e filosóficas dos séculos XVII e XVIII desde a reforma protestante até o advento do Ilumismo, e que pressupõe, essencialmente, uma dimensão de reflexividade que se contrapõe às determinações normativas da tradição e de ordenamentos metafísicos sobre a realidade, estruturando-se como o princípio a partir do qual o sujeito se expressa nas sociedades modernas.

No entanto, ao longo do desenvolvimento dos séculos XIX e XX, o " indivíduo" - enquanto efetivo sujeito do processo social - foi sendo minimizado em relação a um conjunto de forças macrossociais. Isto pode ser percebido deste o desenvolvimento da indústria cultural até o fortalecimento do Estado como estrutura crescente de controle.

No interior da própria teoria social esse processo foi retratado tanto direta quanto indiretamente através das análises que privilegiavam os aspectos estruturais do desenvolvimento da modernidade, seja no âmbito do marxismo seja no plano da análise funcional. ${ }^{7}$

No próprio pensamento de Foucault, o Sujeito também se descentra, estando entremeado pelos processos histórico e social; 
neste caso, não seria um atributo do indivíduo, mas o resultado do próprio movimento imanente da história. Giddens (1999, p. 307), chama a atenção para o fato de que esse movimento levaria, no caso extremo, à possibilidade de pensarmos a história completamente ausente de sujeitos ativos: "o problema é que a história para Foucault parece não ter sujeito ativo nenhum. É história sem ação. Os indivíduos que aparecem nas análises de Foucault mostram-se como que impotentes para determinar seus próprios destinos".

De um modo ou de outro, a partir da segunda metade do século $\mathrm{XX}$, principalmente em suas últimas décadas, podemos perceber um movimento contrário a este processo, aonde o tema da subjetividade retorna com força tanto na atividade social concreta quanto no interior do pensamento social contemporâneo. ${ }^{8}$

O declínio do "Estado social" na Europa associado aos movimentos da contra-cultura e, por fim, o próprio advento da pós-modernidade - esta última marcada pela flexibilização dos significados no interior das práticas sociais e pela fragmentação da atividade social e suas respectivas representações, processo que inequivocamente, acaba por relançar o indivíduo para dentro da arena social -, contribuíram decisivamente para a retomada do tema da subjetividade no contexto da atividade social contemporânea.

Neste sentido, nos parece que a hipertrofia do individualismo no atual estágio de desenvolvimento das sociedades se deve, muito mais do que a mudanças estruturais no plano econômico, tal qual apontado por Harvey (1992), à recuperação de um dos valores centrais da modernidade, no qual o homem torna-se sujeito da atividade social e que, ao longo do século $\mathrm{XX}$, foi soterrado por forças macro-estruturais, irrompendo agora com toda força e a esfera do consumo parece ser o meio privilegiado para tal irrupção.

Se pensarmos a esfera contemporânea do consumo como um sistema de comunicação social, ${ }^{9}$ aonde os diversos produtos e bens 
são constantemente associados a distintos universos significativos e, ainda, que tal associação se dá de maneira cada vez mais flexível, o ato de consumo transforma-se, neste caso, num ato de adesão simbólica em que a escolha do objeto se torna uma escolha estratégica, por meio da qual o consumidor vai continuamente definindo e redefinindo sua identidade.

Nesta perspectiva, a própria constituição de identidades resvala nesse processo de escolhas, mediado pela atividade de consumo, o que pressupõe, efetivamente, uma dimensão de reflexividade.

É exatamente sob este aspecto que a dinâmica do consumo passa a se constituir como um processo de produção de subjetividades, recuperando a dimensão do indivíduo enquanto valor central da modernidade através do ato de consumo enquanto ato de escolha reflexivamente orientado.

Poderíamos assim afirmar que o ato de consumo se caracteriza como uma forma contemporânea de "ação social" que se desdobra - tal qual nos termos desenvolvidos pelo próprio Weber -, em um tipo específico de relação social, definida a partir de um conjunto de significados que a envolvem e que se encontram partilhados por um grupo definido de consumidores.

$\mathrm{O}$ ato de consumo, definido então como substrato de uma relação social, não poderia, sob este aspecto, ser completamente destituído de subjetividade. Neste caso, a relação estabelecida entre o conjunto dos consumidores pressupõe uma relação intersubjetiva, na qual interesses, gostos e preferências, juntamente com as marcas e significados sociais que a acompanham, acabam se entrelaçando por intermédio da prática consumista.

Esta subjetividade vai sendo definida, então, no interior do próprio processo de consumo, não se reduzindo assim a uma subjetividade "psicológica", mas, sim, produzida no interior de um processo social. Poderia a isto se objetar que tal experiência seria 
uma forma dissimulada da individualidade, ou mesmo uma pseudoexpressão desta, tal como formulado, por exemplo, no pensamento de Adorno.

Para Adorno, ao se criar um sistema massificado da cultura pela mercadificação dos bens culturais, a indústria cultural produziria, simultaneamente, a padronização e homogeneização do gosto e das escolhas, retirando desse processo qualquer forma de expressão subjetiva do indivíduo. Tal processo, no entanto, não se apresentaria de forma visível aos homens. Ao contrário, sua realização real pressupõe, dialeticamente, sua negação simbólica. E é aí exatamente que a menção ao indivíduo se tornaria a condição de sobrevivência do sistema enquanto mecanismo de ocultamento de sua real dinâmica de padronização e massificação. ${ }^{10}$

A questão de fundo, no entanto, e que nos parece central na compreensão de todo o processo, estaria ligada a uma outra perspectiva, que remete ao processo de vivenciação simbólica da individualidade.

Parece-nos imprescindível ter em conta que, antes de tudo, o "indivíduo" é uma construção social da modernidade. E, como tal, não se refere, de modo ingênuo e trivial, a um sujeito de carne e osso dotado de uma liberdade total, monádica, gerada por sua racionalidade. Antes, o indivíduo se caracteriza como um ideal moderno. Sua vivenciação simbólica, nos parece, é um ato de sua realização, talvez mesmo a sua possibilidade mais efetiva de existência.

Deste modo, a crítica deflagrada à perda da individualidade ou, ao menos, sua supressão no decorrer do desenvolvimento da modernidade e de suas macro-estruturas parte de um pressuposto: a existência de um indivíduo real, de uma subjetividade purificada e constituída a priori, no limite, uma subjetividade constituída exante, num plano quase transcendente. 
Mas, de fato, onde se encontraria esse "indivíduo" perdido da modernidade? Quando, de fato, ele existiu, ao menos nestes moldes? Estaria esta perda associada ao próprio sentido do declínio da racionalidade iluminista?

Quando Horkheimer (1976) produz a metáfora sobre o indivíduo na modernidade, apontando esta última como "a máquina que expeliu o maquinista", a pergunta que cabe é exatamente a seguinte: quem é este indivíduo que estaria no comando do mundo moderno e que foi destituído ao longo do desenvolvimento da própria modernidade?

Se a crítica ao desenvolvimento dos sistemas e processos de massificação e estandardização social produzida por parte da teoria social contemporânea em relação à dissolução da individualidade faz sentido, ela, no entanto, equivoca-se ao pressupor a existência de um ente singular, real, que estaria sendo ultrapassado por esses sistemas e processos. Ao fazer isso, ela reifica a própria noção de indivíduo como algo absoluto, como um dado da realidade social. Parece-nos, ao contrário, que o que está realmente em jogo seriam, antes de tudo, forças sociais em combate, valores em combate. Exatamente por isso é plausível pensarmos que, mesmo no interior da esfera do consumo, atreladas diretamente ao mercado, possam submergir expressões de subjetividade, mediadas pela atividade consumista.

Neste caso, se podemos pensar a esfera do consumo como espaço para a produção de subjetividades e constituição de identidades, é imprescindível, no entanto, reconhecer a característica de flexibilidade dessas expressões. No interior desta perspectiva seria possível falarmos de "identidades flexíveis", que se organizam a partir de experiências subjetivas mediadas pelos significados presentes e atribuídos aos produtos e bens de consumo. Portanto, o desenvolvimento e a expansão da sociedade de consumo recolocam, tanto quanto ampliam, este valor caro à modernidade, ou seja, o indivíduo, enquanto efetivo sujeito do processo social, 
transformando-se, em uma espécie de "estrutura civilizatória" da própria modernidade.

Se, num primeiro momento, a sociedade de consumo se organizou pelo viés da padronização, onde a diferenciação marcava-se pela proximidade com o estilo de vida e padrão de consumo de algum grupo bem estabelecido e legitimado na sociedade, que se tornava um grupo de referência - procedimento que, aliás, foi determinante no crescimento das indústrias de imitação já a partir de meados do século XVIII na Inglaterra -, no contexto atual de organização da sociedade de consumo, o elemento marcante parece ser a diferenciação pela identificação.

Dito de outro modo, seria plausível afirmar que, no plano da sociedade de consumo contemporânea, marcada por uma cultura ao mesmo tempo altamente fragmentada e objetiva, a questão do "indivíduo" enquanto agente do processo social torna-se imperativa por um motivo especial: ele passa a ser a principal referência para a constituição de identidades, isto é, passa a constituir uma das principais referências a partir da qual grupos e segmentos sociais se formam, de acordo com a absorção de marcos de identificação como símbolos, signos, imagens e representações que se encontram dispostos em um sistema de consumo que compreende desde o mercado até as estruturas de comunicação social, como a indústria cultural e a publicidade.

A questão do "indivíduo" - enquanto elemento estrutural deste processo - torna-se, então, patente, tendo em vista que a "ele" se reporta a consolidação de marcas identitárias, que somente se fixam através de sua "adesão" ou não a tais marcas, encontrando-se estas associadas aos objetos dispostos hierarquicamente no interior do sistema de consumo.

A publicidade desempenha aí um papel fundamental à medida que, através de seu discurso, reafirma a noção de indivíduo enquanto 
efetivo agente do processo social, transfigurado na imagem do indivíduo-consumidor.

Em outras palavras, se identidades são produzidas e definidas dentro do processo de consumo, elas não mais se impõe totalmente de "fora" sobre indivíduos e grupos, formando suas identidades deliberadamente, mas ao contrário, são demarcadas por intermédio de "atos de escolha", através do ato de consumo, juntamente com um conjunto de marcas identitárias que se encontram dispostas no interior do sistema de consumo. Neste caso, o indivíduo, enquanto consumidor, passa a ser também agente no interior desse processo de identificação social.

A seguir, gostaríamos de propor uma aproximação com as idéias desenvolvidas pelo sociólogo norte-americano radicado na Inglaterra, John Thompson, especificamente sobre o aspecto da dinâmica cultural no contexto das sociedades contemporâneas expressa na relação, por ele proposta, entre "formas simbólicas" e "contextos sociais estruturados".

\section{Consumo e expressão de subjetividades em contextos sociais estruturados}

Partindo, de um lado, da idéia desenvolvida por Geertz (1978) da cultura como estruturas simbólicas de significados que são socialmente partilhadas e que se organizam enquanto "textos" passíveis de interpretação tanto pelos agentes envolvidos na interação quanto por aqueles que estabelecem a análise cultural e, de outro, pela noção de campos de interação proposta por Bourdieu (1983), na qual tanto as posições dos agentes quanto os recursos de que dispõem encontram-se estruturados no interior desses campos, John Thompson (1995) irá forjar seu esquema teórico tentando compreender a dinâmica das relações da produção, comunicação 
e recepção dos fenômenos culturais no contexto das sociedades contemporâneas.

Segundo o esquema de Thompson, os fenômenos culturais são denominados "formas simbólicas", as quais se constituem como expressões de significados produzidos nos processos de interação em conexão com os contextos socialmente estruturados nos quais elas se encontram inseridas.

Nessa perspectiva, as formas simbólicas seriam tanto produzidas como textos - compreendendo um conjunto de significados socialmente partilhados e passíveis de interpretação pelos agentes e pela análise cultural -, quanto a partir dos contextos no interior dos quais essas produção e interpretação se dariam.

A proposta de Thompson, neste caso, pressupõe uma tentativa inicial de junção teórica entre elementos propostos por Geertz, especialmente no que tange à dimensão simbólica dos fenômenos culturais e sua constituição enquanto textos carregados de significado, aliada à proposta de Bourdieu que privilegia a dimensão estrutural (enquanto estrutura estruturada) dos campos e as disposições da ação que se encontram encerradas na sua idéia de habitus.

Thompson irá chamar a atenção para o fato de que se as formas simbólicas pressupõem a existência de significados que emergem da interação simbólica entre os agentes, estes significados apenas ganham validade quando inseridos em contextos socialmente estruturados. Nesse caso, nem os significados produzidos na interação são totalmente autônomos, nem os contextos sociais são completamente normativos em relação à ação.

Deste modo, podemos dizer que esses contextos seriam estruturados não na perspectiva clássica do estruturalismo, isto é, como uma ordem determinante que pressupõe o descentramento dos agentes como sujeitos dos processos sociais, mas, ao contrário, 
são estruturados no sentido preciso de um conjunto de posições que se encontram previamente definidas nos campos de interação. A proporcional distribuição de recursos (econômicos, culturais e simbólicos) associados a esses campos, juntamente com as instituições que conjugam em seu interior normas e convenções, e, pelas assimetrias estáveis de relações de poder que norteiam as relações de dominação nesses contextos é que constituiriam, segundo Thompson, sua estrutura, passando, tudo isso conjugado - e mesmo sob distintos níveis de relevância -, a servir de pano de fundo a partir do qual as formas simbólicas são produzidas e gerenciadas. Como aponta em sua análise, essas dimensões

referem-se a diferentes aspectos dos contextos sociais e definem diferentes níveis de análise. (...) Estas características não são simplesmente elementos de um ambiente dentro do qual a ação tem lugar, mas são constitutivos da ação e interação, no sentido de que os indivíduos rotineira e necessariamente, baseiam-se, implementam e empregam os vários aspectos dos contextos sociais no curso de sua ação e interação uns com os outros. As características contextuais não são apenas restritivas e limitadoras: são, também, produtivas e capacitadoras. Elas realmente limitam a variedade de ações possíveis, definindo alguns caminhos como mais apropriados ou com mais possibilidade de serem executados que outros e garantindo que os recursos e oportunidades sejam distribuídos desigualmente. Mas elas também tornam possíveis as ações e interações que ocorrem na vida cotidiana, constituindo-se nas condições sociais das quais dependem, necessariamente, essas ações e interações. (Thompson, 1995, p. 198-199).

Transfigurando o esquema de Thompson para o universo do consumo contemporâneo, poderíamos pensá-lo enquanto: 1) contexto social estruturado, que compreenderia um recorte espaçotemporal especifico, a modernidade tardia, e seu novo modelo de acumulação flexível, suas instituições, desde o mercado em sentido convencional até as lojas de departamentos, a publicidade, os shopping centers e o mercado eletrônico, os quais produziriam uma 
dinâmica normativa diferenciada, desde a relação de preços fixos até a objetivação das relações de compra e venda; 2) estrutura social, marcada pelas assimetrias estáveis quanto à distribuição e aquisição dos bens; 3) campos de interação privilegiados e suas posições e recursos disponíveis, que poderíamos identificar, de um lado, pela valorização econômica dos bens e dos recursos para obtê-los e, de outro, pela valorização simbólica desses bens, aqui marcados pelos princípios da distinção e identificação social.

No interior do universo do consumo, agora pensado enquanto um contexto estruturado, os atos de consumo - compreendidos como atos de escolha simbolicamente carregados de significados - marcariam expressões de subjetividade à medida que os agentes os realizassem a partir da valorização dos significados atribuídos a determinados bens em detrimento de outros, e, nesse caso, essa subjetividade poderia estar associada tanto a um princípio de identificação quanto a um princípio de distinção social, bem como a uma forma simbólica de reprodução dos contextos nos quais tais escolhas se localizam.

Nos dois casos estamos falando em subjetividades que são socialmente constituídas, seja na interação direta entre agentes, seja por intermédio de apropriações de significados e sentidos previamente estabelecidos e legitimados que se encontram associados ao consumo de determinado bem e que são inferidos por agentes externos à interação direta, como, por exemplo, o discurso publicitário.

Parece plausível pensarmos essas expressões de subjetividade tanto através dos mecanismos de valorização intersubjetivos entre agentes, mediados pela aquisição de bens de consumo, quanto como forma de associação desses mesmos agentes com elementos que se encontram previamente estruturados no interior do universo do consumo e que se associam aos bens, atuando como forma de identificação social. 
Nesta perspectiva, enquanto um contexto social estruturado, o universo do consumo estaria servindo, simultaneamente, como espaço de produção e, ao mesmo tempo, como anteparo de mediação através da qual se expressariam subjetividades e identidades.

Parece-nos que esse esquema é bom para pensarmos o universo contemporâneo do consumo por tocar diretamente numa questão que tem sido cara aos estudos sobre a sua própria dinâmica, isto é, o tema da reprodução. Sob um ponto de vista clássico, o tema da reprodução social por intermédio da atividade consumista se encontra demarcada pelo princípio da distinção social.

Desde a tese original de Veblen (1985) que trata o consumo conspícuo como forma de emulação social até a análise desenvolvida por Bourdieu (1979) sobre a legitimidade do gosto, o universo do consumo tem sido pensado predominantemente, embora não exclusivamente, ${ }^{11}$ como uma forma de reprodução de um sistema de relações assimétricas de poder e dominação que se consolida sob uma forma essencialmente simbólica.

Partindo do esquema proposto por Thompson, ao contrário, os processos de valorização das formas simbólicas são passíveis de serem diferenciados de acordo com os contextos sociais em que essas "formas" foram produzidas e onde são recebidas. Como aponta Thompson (1992, p. 201) a esse respeito,

se as características dos contextos sociais são constitutivas da produção das formas simbólicas, são, também, constitutivas dos modos pelos quais essas formas são recebidas e entendidas. Tais formas são recebidas por indivíduos que estão situados em contextos sócio-históricos específicos, e as características sociais desses contextos moldam as maneiras pelas quais as formas simbólicas são por eles recebidas, entendidas e valorizadas. O processo de recepção não é um processo passivo de assimilação; ao contrário, é um processo criativo de interpretação e avaliação no qual o significado das formas simbólicas é ativamente constituído e reconstituído. Os 
indivíduos não absorvem passivamente formas simbólicas mas, ativa e criativamente, dão-lhes um sentido e por isso, produzem um significado no processo de recepção.

Desse ponto de vista, os processos de reprodução da estrutura social podem ser efetivamente redefinidos em favor de mecanismos de valorização simbólica de segmentos e grupos sociais posicionados em "desvantagem" no próprio interior dessa estrutura. Sendo assim, mais do que apenas a reprodução de relações ou posições assimétricas de poder, a dinâmica do consumo pode, através de processos transversais de poder, o que significa a legitimação e espraiamento de padrões de gosto intermediários e populares para o conjunto da sociedade, redefinir a própria dinâmica simbólica das estruturas sociais.

A difusão da telenovela entre os mais variados segmentos sociais seria um bom exemplo deste processo. Originalmente tido como produto de consumo de massa de segmentos sociais intermediários e populares, passa gradativamente a se tornar "objeto" de consumo cultural também de elites, como aponta o interessante estudo de Forjaz (1988) sobre lazer e consumo cultural dos segmentos sociais abastados no Brasil.

Neste sentido, se o processo de consumo pode ser percebido não apenas como campo de reprodução mas, fundamentalmente, como espaço de produção de significados, passa então a constituir um dos contextos mais privilegiados, no interior das sociedades contemporâneas, onde indivíduos e grupos produzem, reproduzem, transformam e expressam suas subjetividades e identidades.

No interior desta perspectiva nos parece ser indispensável, como forma de percepção mais exaustiva da dinâmica contemporânea da relação entre cultura e consumo, sua compreensão menos como uma relação de determinação normativa, determinante e alienante das ações e interações, em favor de uma percepção que a compreende 
como um contexto estruturado a partir do qual, agora, as identidades e subjetividades são construídas e mediatizadas pelo consumo dos bens.

\section{Notas}

1 Uma importante reflexão pautada nesta linha de análise é aquela desenvolvida por C. Campbell (2001).

2 Sob este aspecto, podemos destacar os trabalhos de Jean Baudrillard (1991), Mary Douglas (2006), Pierre Bourdieu (1983), McKendrick, Brewer e Plumb (1982), e, mais recentemente, Feathersthone (1995), Bauman (2005) e Campbell (2001), entre diversos outros.

3 Um exemplo disto é a concepção de Baudrillard (1971) expressa em seu clássico trabalho $A$ sociedade de consumo.

4 Vide por exemplo os trabalhos de Harvey (1992) e Bauman (2001).

5 Como aponta Harvey (1992, p. 161) a este respeito, “[...] o movimento mais flexível do capital acentua o novo, o fugidio, o efêmero, o fugaz e o contingente da vida moderna, em vez dos valores mais sólidos implantados na vigência do fordismo. Na medida em que a ação coletiva se tornou, em conseqüência disso, mais difícil - tendo essa dificuldade constituído, com efeito, a meta central do impulso de incremento do controle do trabalho -, o individualismo exacerbado se encaixa no quadro geral como condição necessária, embora não suficiente, da transição do fordismo para a acumulação flexível".

6 Sobre este movimento de departamentalização nas empresas com vistas a uma maior racionalidade sobre o mercado, consultar Levitt (1991).

7 Bom exemplo disto são as obras, no campo do marxismo, de Louis Althusser e N. Poulantzas e, no âmbito da análise funcionalista, os projetos teóricos de Talcot Parsons e Robert Merton.

8 Entre as mais diversas abordagens, podemos citar os trabalhos de F. Guatarri (1986), Alain Touraine (1994), Stuart Hall (1998), Gilles Lipovetsky (1983), entre outros. 
9 Esta é, por exemplo, uma idéia presente no trabalho de Douglas e Iserwood (2006) que, apesar de ser uma importante contribuição aos estudos sobre o universo da demanda, peca pela sua proposta de produzir uma teoria universal e ahistórica do consumo.

10 A seguinte passagem é paradigmática a respeito deste processo: "tanto no adorador fetichista dos bens de consumo como no de 'caráter sadomasoquista' e no cliente da arte de massas de nosso tempo, verifica-se o mesmo fenômeno, sob aspectos diversos. A masoquista cultura de massas constitui a manifestação necessária da própria produção onipotente. A ocupação efetiva do valor de troca não constitui nenhuma transubstanciação mística. Corresponde ao comportamento do prisioneiro que ama a sua cela porque não lhe é permitido amar outra coisa. A renúncia à individualidade, que se amolda à regularidade rotineira daquilo que tem sucesso bem como fazer o que todos fazem, segue-se do fato básico de que a produção padronizada dos bens de consumo oferece praticamente todos os mesmos produtos a todo cidadão. Por outra parte, a necessidade, imposta pelas leis do mercado, de ocultar tal equação conduz à manipulação do gosto e à aparência individual da cultura oficial, a qual forçosamente aumenta na proporção em que se agiganta o processo de liquidação do indivíduo. Tanto que, no âmbito da superestrutura, a aparência não é apenas o ocultamento da essência, mas resulta imperiosamente da própria essência. A igualdade dos produtos oferecidos, que todos devem aceitar, mascarase no rigor de um estilo que se proclama universalmente obrigatório; a ficção da relação de oferta e procura perpetua-se nas nuanças pseudoindividuais."

11 Sobre este aspecto vide, por exemplo, as tentativa de distanciamento desta perspectiva desenvolvida por Douglas e Isherwood (2006), Michel de Certeau (1998) e, mais recentemente, Campbell (2001).

The (re)construction of the individual: the consumer society as a "social context" of the production of subjectivities

Abstract: The present work makes an analysis on the contemporary consumer society and on the new relationships as well as new social processes that have been produced in its context. Despite some 
classical thesis that comprehend consumer society's expansion as a massification/homogenization process and that oust the individual as a subject of the social process, for example, some approaches of the Frankfurt School, especially in Adorno's and Hokheimer's works, we intended to discuss how we could comprehend the movement of consumption expansions as an inverse movement, essentially marked for an individuation process that takes place in new forms of construction of identities and subjectivities in the contemporary society. The theoretical scheme produced by the American sociologist John Thompson (1995) was used to comprehend consumer society as a "structured social context" from where "symbolical forms" are constructed as expressions of social subjectivity.

Keywords: consumer society, contemporary culture, identities, individuality, subjectivities.

\section{Referências bibliográficas}

ADORNO, T.; HORKHEIMER, M. O iluminismo como mistificação das massas. In: LIMA, Luiz C. (Org.). Teoria da cultura de massa. 4 ed. Rio de Janeiro: Paz e Terra, 1990.

ADORNO, T. O fetichismo na música e a regressão da audição. In: BENJAMIN, W.; HABERMAS, J.; HORKHEIMER, M.; ADORNO, T. W. Textos escolhidos. São Paulo: Abril Cultural, 1983. (Coleção os pensadores). p.165-191.

BAUDRILLARD, Jean. A sociedade de consumo. Lisboa: Ed. 70, 1991.

. À sombra das maiorias silenciosas. 3. ed. São Paulo: Brasiliense, 1993.

BAUMAN, Z. A modernidade liquida. Rio de Janeiro: Zahar, 2001. . Globalização. Rio de Janeiro: Zahar, 2005.

BELL, Daniel. O advento da sociedade pós-industrial. São Paulo: Cultrix, 1973.

BENJAMIM, Walter. A obra de arte na época de suas técnicas de reprodução. In: BENJAMIN, W.; HABERMAS, J.; HORKHEIMER, 
M.; ADORNO, T. W. Textos escolhidos. São Paulo: Abril Cultural, 1983. (Coleção os pensadores).

BOURDIEU, Pierre. La distinction. Paris: Les Éditions de Minuit, 1979.

- Sociologia. Org. por Renato Ortiz. São Paulo: Ática, 1983. (Grandes Cientistas Sociais, v. 39).

CAMPBELL, Colin. A ética romântica e o espírito do consumismo moderno. Rio de Janeiro: Rocco, 2001.

CERTEAU, M. A invenção do cotidiano: artes do fazer. Petrópolis: Vozes, 1998.

CORRIGAN, Peter. Objects, commodities e non-commodities. In:

The sociology of consumption. London: Sage, 1979.

DOUGLAS, Mary; ISHERWOOD, Baron. O mundo dos bens: para uma antropologia do consumo. Rio de Janeiro: Ed. UFRJ, 2006.

ELIAS, Norbert. O processo civilizador: uma história dos costumes. Rio de Janeiro: Zahar, 1990.

EWEN, Stuart. Capitains of consciousness: advertising and the social roots of the consumer culture. New York: McGraw-Hill, 1977.

FAETHERSTONE, M. Cultura de consumo e pós-modernismo. São Paulo: Studio Nobel, 1995.

FRASER, W.H. The coming of the mass market: 1850-1914. London: The Macmillan Press, 1981.

FORJAZ, M. C. S. Lazer e consumo cultural das elites. Revista Brasileira de Ciências Sociais, São Paulo, n. 6. v. 3, 1988.

GEERTZ, Clifford. A interpretação das culturas. Rio de Janeiro: Zahar, 1973.

GATARRI, Félix. Micropolitica: cartografias do desejo. Petrópolis: Vozes, 1986. 
GUIDDENS, Anthony. As conseqüências da modernidade. São Paulo: UNESP, 1991.

GUIDDENS, Anthony. Estruturalismo, pós-estruturalismo e a produção da cultura. In: GUIDDENS, A.; TURNER, J. Teoria social hoje. São Paulo: UNESP, 1999.

HALL, Stuart. A identidade cultural na pós-modernidade. 2. ed. Rio de Janeiro: DP\&A, 1998.

HARVEY, David. Condição pós-moderna. São Paulo: Loyola, 1992.

HABERMAS, Jürgen. Comunicação, opinião pública e poder. In: CONH, G. (Org.). Comunicação, opinião pública e poder. São Paulo: Ática, 1986.

HORKHEIMER, Max. O conceito de iluminismo. In: BENJAMIN, W.; HABERMAS, J.; HORKHEIMER, M.; ADORNO, T. W. Textos escolhidos. São Paulo: Abril Cultural, 1983. (Coleção os pensadores).

HORKHEIMER, Max. Eclipse da razão. Rio de Janeiro: Ed. Labor do Brasil, 1976.

LEVITT, T. A imaginação do marketing. São Paulo: Atlas, 1991.

LIPOVETSKY, Gilles. O império do efêmero. São Paulo: Cia das Letras, 1991.

. A era do vazio: ensaio sobre o individualismo contemporâneo. Lisboa: Relógio D’Água, 1983.

McKENDRICK, N.; BREWER, J.; PLUMB, J. H. The birth of a consumer society: the commercialization of eighteenth-century England. Indiana: Indiana University Press, 1982.

OFFE, Clauss. Capitalismo desorganizado. São Paulo: Brasiliense, 1989.

ORTIZ, Renato. Cultura e modernidade. São Paulo: Brasiliense, 1991. 
ORTIZ, Renato. A escola de Frankfurt e a questão da cultura. Revista Brasileira de Ciências Sociais, São Paulo, v. 1, n. 1, 1986.

RETONDAR, Anderson. Sociedade de consumo, modernidade e globalização. São Paulo: Annablume; Campina Grande: EDUFCG, 2007. . As galerias da modernidade-mundo. Revista de Ciências Humanas, Universidade Gama Filho, Rio de Janeiro, 2001.

SENNETT, Richard. O declínio do homem público. São Paulo: Cia. das Letras, 1993.

THOMPSON, John. Ideologia e cultura moderna: teoria social crítica na era dos meios de comunicação de massa. Petrópolis, RJ: Vozes, 1995.

. The new visibility. Theory, Culture and Society, v. 22, n. 6, 2005.

. Tradition and self in a mediated world. In: HEELAS, P.; LASH, S.; MORRIS, P. (Eds.). Detraditionalization. Oxford: Blackwell, 1996.

TOURAINE, Alan. Crítica da modernidade. Petrópolis: Vozes, 1994.

VEBLEN, T. Teoria da classe ociosa. In: . A Alemanha imperial e a Revolução Industrial; A teoria da classe ociosa. São Paulo: Victor Civita, 1985. (Coleção os pensadores).

WEBER, Max. A ética protestante e o espirito do capitalismo. São Paulo: Pioneira, 1987. . Economia e sociedade. Brasília, DF: Ed. UnB, 1991. v. 1.

WILLIAMS, Raymond. Cultura. São Paulo: Paz e Terra, 1992. 